\title{
Surgical procedure versus medical treatment for infective endocarditis associated to mortality in Mexican population
}

\section{Procedimiento quirúrgico versus tratamiento médico de la endocarditis infecciosa y factores de riesgo asociados a la mortalidad en población mexicana}

\author{
José A. Alvarado-Alvarado1*, Gildardo Vidal-Morales², Ricardo I. Velázquez-Silva1, Arturo Ortiz-Álvarez \\ Rodrigo Torres-Velázquez ${ }^{1}$, Jesús D. Velázquez-Orta1 ${ }^{1}$,Martín Magaña-Aquino ${ }^{3}$, and \\ Marco U. Martínez-Martínez ${ }^{1,4}$
}

${ }^{1}$ Department of Internal Medicine; 2Department of Cardiology; ${ }^{3}$ Department of Infectology. Hospital Central "Dr. Ignacio Morones Prieto", San Luis Potosí; ${ }^{4}$ Hospital General de Zona No. 1, Instituto Mexicano del Seguro Social, San Luis Potosí, México

\begin{abstract}
Background: Early surgical procedures on patients with infective endocarditis (IE) have shown a clearly benefit to reduce embolization at the central nervous system. We conducted a retrospective cohort in Mexican population to evaluate mortality and clinical outcomes in patients with IE with or without surgical intervention. Objectives: Our aim was to evaluate factors associated with mortality in patients with IE and compare both groups with and without a surgical intervention. Methods: We evaluated a retrospective cohort of patients who had been diagnosed with IE according to the Duke's criteria at our Institution in SLP, Mexico, from January 2001 to September 2016. We compared the risk factors associated to mortality of patients with or without surgery. Our primary outcome was mortality within 6 months of follow-up after the diagnosis. Results: We included 105 patients, 51 (48.6\%) were men, median age 46 [Q1 30, Q3 59] years, 36 patients (34.3\%) received surgical treatment (STG), and 69 (65.7\%) only medical treatment (MTG) group; 41 patients (39\%) died during the study period; in the surgery group eight patients died (22\%); and 33 in the MT group (47\%) $p=0.049$. Adjusted for APACHE II, surgery, creatinine levels and the size of vegetation, the surgery group had lower mortality than patients on MTG (HR 0.36, $p=0.047$ ). Conclusion: As previously described in the literature, patients who underwent surgery had lower mortality than the patients who only received medical treatment; however, the Mexican population is different to other populations group, due to higher risk of diabetes mellitus (28\%) versus (10\%) in global risk of DM in the world and its complications and other chronic diseases as arterial systemic hypertension. Thus, surgical treatment must be elected as goal standard treatment in patient's whit IE and presence of vegetation.
\end{abstract}

Key words: Infective endocarditis. Medical treatment. Mortality. Surgical procedure.

\section{Resumen}

Antecedentes: Los procedimientos quirúrgicos tempranos en pacientes con endocarditis infecciosa (EI) han mostrado un beneficio claro para reducir la embolización en el sistema nervioso central. Realizamos una cohorte retrospectiva en población mexicana para evaluar la mortalidad y los resultados clínicos en pacientes con El con o sin intervención quirúr-

Correspondence:

*José A. Alvarado-Alvarado

E-mail: alfredo_alvarado290@ hotmail.com
Available online: $20-01-2021$ Arch Cardiol Mex. 2021;91(4):458-464 www.archivoscardiologia.com 1405-9940 / @ 2020 Instituto Nacional de Cardiología Ignacio Chávez. Published by Permanyer. This is an open access article under the CC BY-NC-ND license (http://creativecommons.org/licenses/by-nc-nd/4.0/). 
gica. Objetivos: Nuestro objetivo fue evaluar los factores asociados a la mortalidad en pacientes con endocarditis infecciosa y comparar ambos grupos con y sin intervención quirúrgica. Métodos: Evaluamos una cohorte retrospectiva de pacientes que habían sido diagnosticados de El según los criterios de Duke en nuestra Institución en SLP, México, desde enero de 2001 a septiembre de 2016. Comparamos los factores de riesgo asociados a la mortalidad de pacientes con o sin cirugía. Nuestro resultado primario fue la mortalidad dentro de los 6 meses de seguimiento después del diagnóstico. Resultados: Se incluyeron 105 pacientes, 51 (48.6\%) eran hombres, mediana de edad46 [Q1 30, Q3 59] años, 36 pacientes (34.3\%) recibieron tratamiento quirúrgico (STG) y 69 (65.7\%) solo grupo de tratamiento médico (MTG); 41 pacientes (39\%) murieron durante el período de estudio; en el grupo de cirugía fallecieron 8 pacientes (22\%) y en el grupo de MT (47\%) $33 p=0.049$. Ajustado por APACHE II, cirugía, niveles de creatinina y tamaño de la vegetación, el grupo de cirugía tuvo menor mortalidad que los pacientes en MTG (HR 0.36, $p=0.047$ ). Conclusión: Como se ha descrito anteriormente en la literatura, los pacientes que se sometieron a cirugía tuvieron menor mortalidad que los pacientes que solo recibieron tratamiento médico, sin embargo, la población mexicana es diferente a otros grupos poblacionales, debido a un mayor riesgo de diabetes mellitus $(28 \%)$ vs (10\%) en otros países y sus complicaciones y otras enfermedades crónicas como hipertensión arterial sistémica. Por tanto, el tratamiento quirúrgico debe ser elegido como principal método de tratamiento en pacientes con endocarditis infecciosa y presencia de vegetaciones.

Palabras clave: Endocarditis infecciosa. Tratamiento médico. Mortalidad. Procedimiento quirúrgico.

\section{Introduction}

Infective endocarditis (IE) has an annual incidence of 3-9 cases $/ 100,000$. Multiple studies suggest auxiliary diagnoses tests for early and timely diagnosis to decrease morbidity ${ }^{1-3}$. Despite medical progress in surgical procedures and medical treatments, IE is a disease that has a high mortality $(30-80 \%)^{4-7}$. Surgical procedures may reduce significantly composite morbidity and mortality in hospital complications $\mathbf{s}^{8,9}$.

According to the American College of Cardiology and European Society of Cardiology guidelines, the criteria for a surgical procedure on endocarditis of the left heart valve are: cardiac events (heart failure, moderate or severe regurgitation, abscess, and dehiscence or perforation), embolization prevention (vegetation greater than $10 \mathrm{~mm}$ with embolization to the central nervous system and/or great mobility, and vegetation greater than $15 \mathrm{~mm}$ ) and uncontrolled infection (persistent fever or positive blood cultures after 5 days with medical treatment, infection due to fungi or multi-resistant bacteria) ${ }^{1-3,10-13}$. Indications for right heart valve vegetation include: microorganisms (fungi or failure to eradicate them), vegetation greater than $20 \mathrm{~mm}$ with recurrent pulmonary embolism, or right heart failure due to tricuspid regurgitation with a poor response to medical treatment ${ }^{14}$. Surgery is suggested in the first 4-week period, but patients with these criteria having unstable hemodynamic state or hemorrhagic vascular event a 4-week delay of the surgical procedure is recommended ${ }^{15}$. We compared the risk factors associated to mortality of patients with or without surgery. Our primary outcome was mortality within 6 months of follow-up after the diagnosis.

\section{Materials and methods}

We conducted a retrospective cohort study in patients diagnosed with IE at our Institution, from January 2001 to September 2016. Patients were evaluated if they were treated with either a surgery or medical treatment. The study protocol was accepted by the Institutional Ethics Committee. We designed the study according to the principles of the Helsinki Declaration.

\section{Patient selection}

Patients older than 15 years with a definitive diagnosis of IE according to the Duke's Criteria were included; (1) all included patients had echocardiographic evidence of vegetation in any of the cardiac valves.

\section{Data collection}

Medical records were reviewed for patient demographics, comorbidities, initial laboratory findings, predisposing cardiac conditions, echocardiographic findings, cardiac surgery, as well as concomitant complications. Acute Physiology and Chronic Health Evaluation (APACHE) IV and Glasgow Coma Scale (GCS) were calculated based on the variables within the first $24 \mathrm{~h}$ of admission to the hospital. 


\section{Statistical analysis}

Descriptive statistics are shown as a mean \pm standard deviation or median and interquartile range (IQR) according their distribution; categorical variables as percentages. In the comparison of surgical versus medical treatment group, categorical variables were compared with $\chi^{2}$ or Fisher's exact test; continuous variables were compared using student's T or MannWhitney's U-tests analysis. Because of the difference of follow-up, a survival analysis was performed to determine factors associated with mortality. Categorical variables were compared with the log-rank test; multivariate analysis was performed with Cox proportional-hazards models which included the variables that had a $p$-value lower than 0.1 . We describe the hazard ratios with a $95 \%$ confidence interval that was derived from the Cox proportional-hazards model for bivariate and multivariate analysis. Statistical analysis was performed with Rcmdr program (version 3.5.0).

\section{Results}

\section{Participants}

From January 2001 to September 2016, we included 105 patients who met the inclusion criteria at our Institution. The incidence rate observed was 7.32 cases/10,000 admissions/year. The global mortality rate for IE was of $36 \%$.

Baseline characteristics are shown in table 1. The median of age of our cohort was of 46 years, 51 (48.6\%) of patients were men. Four patients $(3.8 \%)$ were intravenous drug user; thirty patients $(28.6 \%)$ had diabetes mellitus; and 33 patients (31.4\%) had chronic kidney disease (CKD). The distributions of affected valves were: left-sided valve (mitral and aortic valves) in 65 patients $(61.9 \%)$ and right-sided valve (tricuspid and pulmonary valves) in 40 patients (38\%). Prosthetic valves were involved in three patients $(2.9 \%)$. Heart failure (48 cases, $45.71 \%$ of patients) was the most common complication.

In addition, the bivariate analysis between MTG and STG is shown, observing a higher prevalence of CKD in the MTG and greater valvular complications in the STG.

\section{Comparative analysis of both groups}

In the bivariate analysis (Table 2), surgical treatment was associated to a lower mortality; however, patients in the medical treatment had a higher frequency of comorbidities (Charlson score), and a higher frequency of chronic kidney disease (creatinine levels and substitutive renal therapy).

\section{Survival analysis}

Because of the differences in comorbidities between the medical and surgical groups, we performed a survival analysis to evaluate factors associated with mortality; moreover, we performed a multivariate Cox-regression analysis to evaluate if the surgical treatment is an independent factor associated with improvement in survival. In the bivariate survival analysis, we found that patients who died had: higher creatinine levels, higher APACHE II score, vegetation of more than 15 $\mathrm{mm}$ and had lower frequency of surgery (Table 2, Fig. 1).

For the multivariate survival analysis, we include as variables in the model creatinine, vegetation $>15 \mathrm{~mm}$, surgery, and APACHE II. Adjusted for APACHE II, size of vegetation and creatinine, surgery was an independent protective factor to death (Fig. 2). Adjusted for APACHE II surgery, creatinine levels and the size of vegetation, the surgery group had lower mortality than patients on medical treatment group (HR 0.36, $p=0.047$ ) (Table 3).

\section{Discussion}

Even though the criteria for surgery are well-described, a surgical procedure can be limited for other comorbidities and severity of the disease. In our cohort, not all patients who accomplish criteria of surgery were operated due to clinical instability according to clinical guidelines management. Our first analysis shows that patients who underwent a surgery had lower comorbidities and lower frequency of renal failure. The survival analysis showed that even to adjust for severity (APACHE score) and other factors, mortality surgical procedure showed a reduction in mortality compared with medical treatment. Studies have shown that surgical procedure reduces embolization at central nervous system, without reducing mortality. In our study, we found a relationship between a surgical procedure and the reduction of this; our results agree with the described by Cabell et al. ${ }^{16}$. In addition, our study describes a global mortality of $39 \%$ similar to that reported in medical literature ${ }^{1-3,10,11 .}$

We adjusted the impact in mortality of surgery in the multivariate analysis for variables which had an impact 
Table 1. Baseline characteristics

\begin{tabular}{|c|c|c|c|c|}
\hline & All $(n=105)$ & MTG $(n=69)$ & STG $(n=36)$ & p-value \\
\hline Male (\%) & $51(48.6)$ & $34(49.3)$ & $17(47.2)$ & 0.842 \\
\hline Age (median $[I Q R])^{*}$ & $46[30,59]$ & $46[30,60]$ & $45.5[31,51.3]$ & 0.38 \\
\hline Age $>60(\%)$ & $27(25.7)$ & $19(27.5)$ & $8(22.2)$ & 0.554 \\
\hline DM2 (\%) & $30(28.6)$ & $21(30.4)$ & $9(25.0)$ & 0.558 \\
\hline CKD (\%) & $30(28.5)$ & $27(39.0)$ & $3(8.3)$ & 0.001 \\
\hline Arterial Systemic Hypertension (\%) & $44(41.9)$ & $27(39.13)$ & $17(47.22)$ & 0.29 \\
\hline Previous IE (\%) & $3(2.9)$ & $2(2.9)$ & $1(2.8)$ & 1 \\
\hline Charlson > $2(\%)$ & $46(43.8)$ & $35(50.7)$ & $11(30.6)$ & 0.048 \\
\hline Seizures (\%) & $98(93.3)$ & $63(91.3)$ & $35(97.2)$ & 0.418 \\
\hline GCS (median $[I Q R])^{*}$ & $15[14,15]$ & $15[14,15]$ & $15[15,15]$ & 0.482 \\
\hline Creatinine $\mathrm{mg} / \mathrm{dl}($ median [IQR])* & $1.2[0.8,6.0]$ & $2.0[0.9,7.8]$ & $1.0[0.7,1.9]$ & 0.003 \\
\hline Creatinine $>2(\%)$ & $41(39.0)$ & $34(49.3)$ & $7(19.4)$ & 0.003 \\
\hline APACHE (median [IQR])* & $16[13,21]$ & $17[13,21]$ & $15[12,20]$ & 0.515 \\
\hline HDAccess (\%) & $29(27.6)$ & $27(39.1)$ & $2(5.6)$ & $<0.001$ \\
\hline$H F(\%)$ & $48(45.7)$ & $29(42.0)$ & $19(52.8)$ & 0.294 \\
\hline LVEF (median [IQR])* & $60[49,65]$ & $60[49,65]$ & $64[49.5,67.3]$ & 0.188 \\
\hline PAP (median [IQR])* & $40[35,47.5]$ & $40[34.3,47.5]$ & $40.5[35,45.8]$ & 0.885 \\
\hline Aneurysm (\%) & $2(1.9)$ & $1(1.4)$ & $1(2.8)$ & 1 \\
\hline Valve Perforation (\%) & $24(22.9)$ & $9(13)$ & $15(41.7)$ & 0.001 \\
\hline Valve Rupture (\%) & $19(18.1)$ & $10(14.5)$ & $9(25)$ & 0.184 \\
\hline Valve Dehiscence (\%) & $1(1.0)$ & $1(1.4)$ & $0(0.0)$ & 1 \\
\hline PHV (\%) & $3(2.9)$ & $2(2.9)$ & $1(2.8)$ & 1 \\
\hline Valve Abscess (\%) & $2(1.9)$ & $1(1.4)$ & $1(2.8)$ & 1 \\
\hline Regurgitation (\%) & $90(85.7)$ & $56(81.2)$ & $34(94.4)$ & 0.065 \\
\hline Vegetation > $15 \mathrm{~mm}(\%)$ & $46(43.8)$ & $27(39.1)$ & $19(52.8)$ & 0.181 \\
\hline Vegetation > $20 \mathrm{~mm}(\%)$ & $51(48.6)$ & $24(34.8)$ & $27(75.0)$ & $<0.001$ \\
\hline Multi-valve (\%) & $50(47.6)$ & $24(34.8)$ & $26(72.2)$ & $<0.001$ \\
\hline Left valve (\%) & $65(61.9)$ & $43(62.3)$ & $22(61.1)$ & 0.904 \\
\hline Fw months (median [IQR])* & $44[20,147]$ & $43.00[17,210]$ & $44[30.3,92.8]$ & 0.72 \\
\hline
\end{tabular}

*Median [range I01-I03] I.

CKD: Chronic Kidney Disease; DM2: diabetes mellitus type 2; Fw: follow-up; GCS: Glasgow Coma Scale; HDAcces: Hemodialysis Access; HF: heart failure;

IE: infective endocarditis; LVEF: left ventricle ejection fraction; PAP: pulmonary artery pressure; PHV: prosthetic heart valve.

in the bivariate analysis. The variables that showed statistically significant differences were: APACHE scale and surgical procedure, mentioning that patients with a multiple organic failure measured by parameters of the APACHE scale have a higher mortality. The surgical procedure was seen to have an independent influence improving the mortality similar to the described in the literature ${ }^{17}$.

The limitations of our study are inherent to its retrospective design and being single-center study. It is 
Table 2. Bivariate analysis based on mortality

\begin{tabular}{|c|c|c|c|}
\hline & \multicolumn{3}{|c|}{$n=105$} \\
\hline & Dead ( $n=41,39 \%)$ & Alive ( $n=64,61 \%$ ) & p value (HR, CI) \\
\hline Gender & & & 0.44 \\
\hline Male $(n=51,48.57 \%)$ & $21(20)$ & $30(28.57)$ & \\
\hline Female $(n=54,51.43 \%)$ & 20 (19) & $34(32.3)$ & \\
\hline $\operatorname{Age}^{*}$ & 45.09 & 46.11 & 0.78 \\
\hline Diabetes Mellitus & $12(11.42)$ & 18 (17.14) & 0.45 \\
\hline Chronic Renal Disease & $13(12.38)$ & $17(16.19)$ & 0.36 \\
\hline Heart Failure & $16(15.23)$ & $32(30.47)$ & 0.29 \\
\hline Creatinine $>2 \mathrm{mg} / \mathrm{dl}$ & $21(20)$ & $20(19.04)$ & 0.03 \\
\hline Charlson $>2$ & $20(19.04)$ & $26(24.76)$ & 0.53 \\
\hline Pulmonary artery pressure ${ }^{* *}$ & 40 & 40 & 0.62 \\
\hline Treatment/procedure & & & 0.049 (HR 0.37, CI 0.12-0.99) \\
\hline Medical treatment & $33(31.42)$ & $36(34.28)$ & \\
\hline Surgical procedure & $8(7.6)$ & $28(26.66)$ & \\
\hline Vegetation higher than $15 \mathrm{~mm}$ & $21(20)$ & $25(23.8)$ & 0.05 \\
\hline Left-sided valve & $24(0.95)$ & $38(38)$ & 0.52 \\
\hline Prosthetic heart valve & $1(1)$ & $2(1.9)$ & 0.49 \\
\hline Left ventricle ejection fraction** & 60 & 61 & 0.07 \\
\hline Abscess & $1(0.95)$ & $1(0.95)$ & 1 \\
\hline Perforation & $5(4.7)$ & $19(18.09)$ & 0.152 \\
\hline Dehiscence & $0(0)$ & $1(0.95)$ & 0.54 \\
\hline Multi-valve & 19 (18.09) & 31 (29.52) & 0.93 \\
\hline Rupture & $7(6.66)$ & $12(11.42)$ & 0.83 \\
\hline Glasgow coma scale** & 14 & 15 & 0.005 \\
\hline APACHE* & $18.86 \pm 7.5$ & $14.35 \pm 6.7$ & 0.005 \\
\hline
\end{tabular}

* Mean \pm Standard Deviation.

**Median [range I01-I03].

HR: hazard ratio; $\mathrm{Cl}$ : $95 \%$ confidence interval.

Table 3. Multivariable logistic regression model for mortality, including variables that were determined a priori to be clinically significant in affecting outcome in EI

\begin{tabular}{|l|c|c|}
\hline & HR, (CI) & p value \\
\hline Surgical Procedure & $0.43,(0.19-0.95)$ & 0.047 \\
\hline APACHE & $1.14,(1.07-1.2)$ & 0.001 \\
\hline Left Ventricle Ejection fraction & $0.97(0.93-1.01)$ & 0.16 \\
\hline Glasgow Coma Scale & $0.88(0.74-1.05)$ & 0.16 \\
\hline
\end{tabular}

HR: hazard ratio; Cl: 95\% confidence interval. convenient to conduct a prospective study to validate our findings and, thus, demonstrate the superiority of surgical procedure.

Despite advances in the diagnosis and treatment of IE, its mortality is high. El has many significant predictors of mortality such as cardiac events (heart failure, moderate or severe regurgitation, etc.), embolization to the central nervous system, and uncontrolled infection, so the use of strategies such as the surgical treatment is essential to improve mortality. 


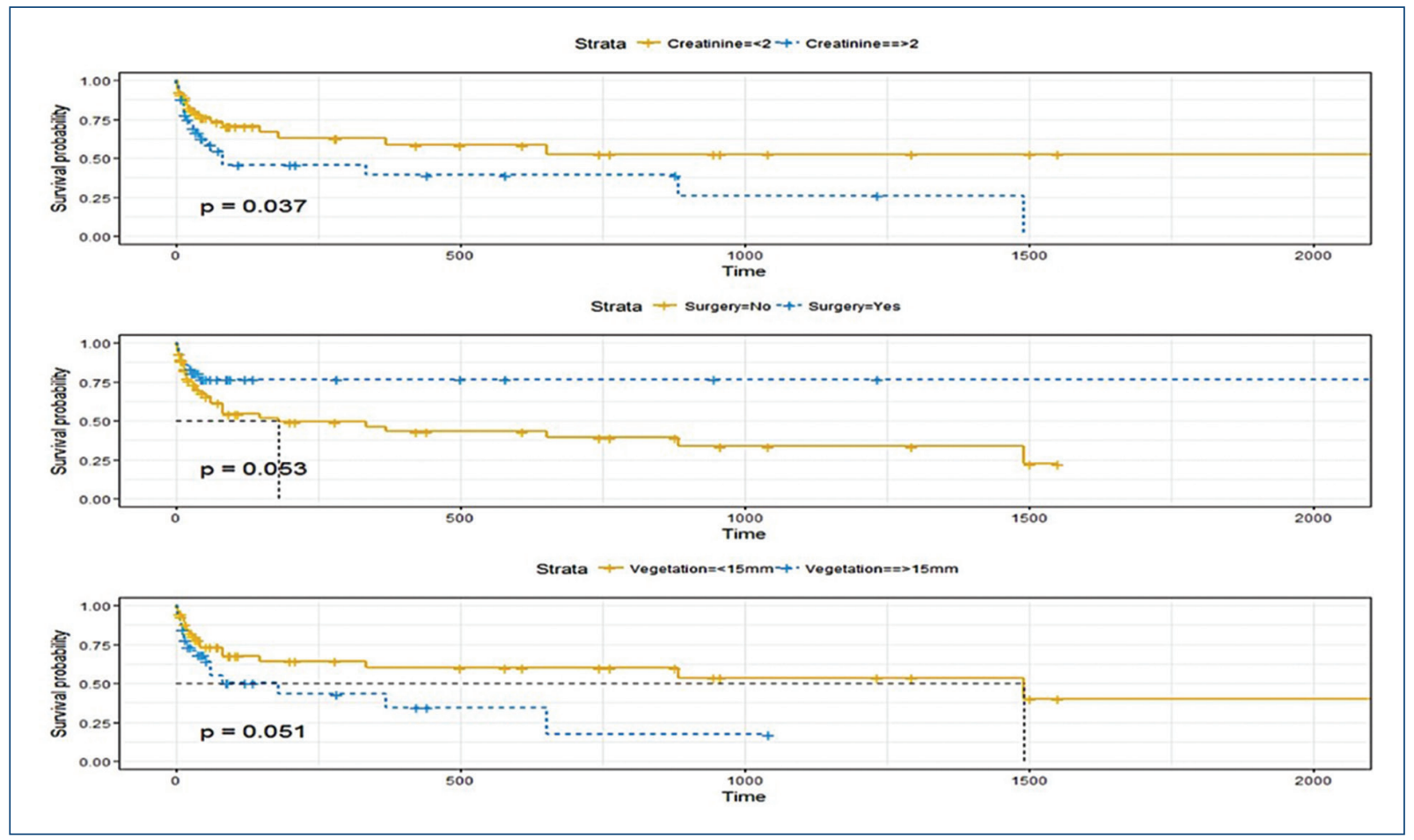

Figure 1. Kaplan-Meier curve for the survival probability.

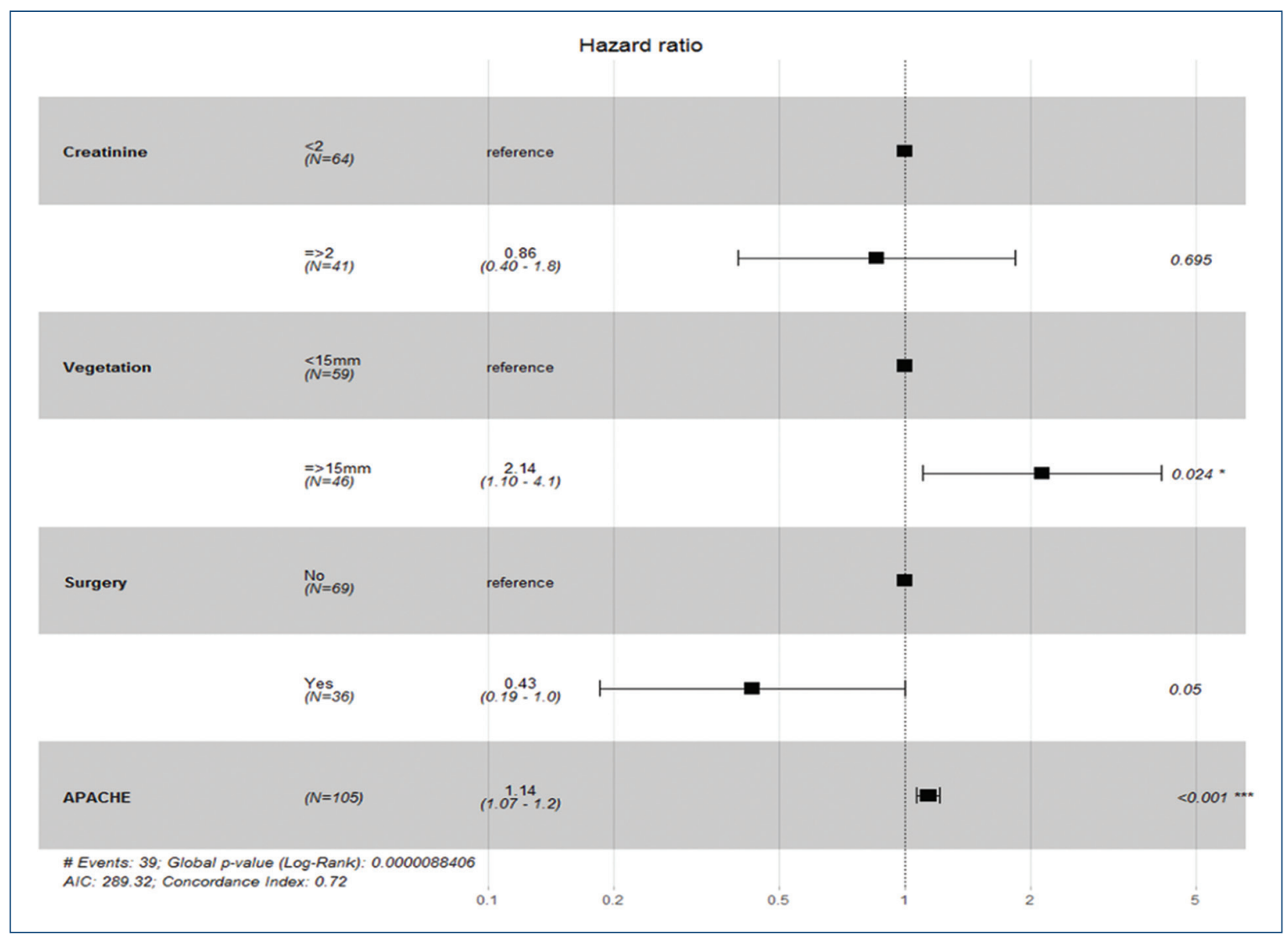

Figure 2. Subgroup analyses of mortality for the variables with statistical difference in bivariate survival analysis. 


\section{Conclusion}

Overall, patients treated with a surgical procedure had a greater survival than patients with medical treatment, regardless of their severity measured by APACHE scale and age.

\section{Funding}

None.

\section{Conflicts of interest}

None.

\section{Ethical disclosures}

Protection of human and animal subjects. The authors declare that no experiments were performed on humans or animals for this study.

Confidentiality of data. The authors declare that they have followed the protocols of their work center on the publication of patient data.

Right to privacy and informed consent. The authors declare that no patient data appear in this article.

\section{References}

1. Habib G, Lancellotti $P$, Antunes MJ, Bongiorni MG, Casalta J P, Del Zotti F, et al. 2015 ESC Guidelines for the management of infective endocarditis. Eur Heart J. 2015;36(44):3075-128.
2. Gomes A, Glaudemans AW, Touw DJ, van Melle JP, Williems TP, Maass $\mathrm{AH}$, et al. Diagnostic value of imaging in infective endocarditis: a systematic review. Lancet Infect Dis. 2017;17(1):e1-14.

3. Kouijzer IJ, Vos FJ, Janssen MJ, van Dijk AP, Oyen WJ, Bleeker-Rovers CP. The value of 18F-FDG PET/CT in diagnosing infectious endocarditis. Eur J Nucl Med Mol Imaging. 2013;40(7):1102-7.

4. Haldar SM, O'Gara PT. Infective endocarditis: diagnosis and management. Nat Clin Pract Cardiovasc Med. 2006;3(6):310-7.

5. Hasbun R, Vikram HR, Barakat LA, Buenconsejo J, Quangliarello VJ. Complicated left-sided native valve endocarditis in adults: risk classification for mortality. JAMA. 2003;289(15):1933-40.

6. San Román JA, López J, Vilacosta I, Luaces M, Sarriá C, Revilla A, et al. Prognostic stratification of patients with left-sided endocarditis determined at admission. Am J Med. 2007;120(4):369.e1-7.

7. Nomura A, Omata F, Furukawa K. Risk factors of mid-term mortality of patients with infective endocarditis. Eur J Clin Microbiol Infect Dis. 2010;29:1355-60.

8. Kang DH, Kim YJ, Kim SH, Sun BJ, Kim DH, Yun SC, et al. Early surgery versus conventional treatment for infective endocarditis. N Engl J Med. 2012;366(26):2466-73.

9. Thuny F, Grisoli D, Collart F, Habib G, Raoult D. Management of infective endocarditis: challenges and perspectives. Lancet (London, England). 2012;379(9819):965-75.

10. Leitman M, Dreznik Y, Tyomkin V, Fuchs T, Krakover R, Vered Z. Vegetation size in patients with infective endocarditis. Eur Heart J Cardiovasc Imaging. 2012;13(4):330-8.

11. Kang DH. Timing of surgery in infective endocarditis. Heart. 2015; 101(22):1786-91.

12. Benito N, Miró JM, de Lazzari E, Cabell CH, del Río A, Altclas J, et al. Health care-associated native valve endocarditis: importance of non-nosocomial acquisition. Ann Intern Med. 2009;150(9):586-94.

13. Duval X, lung B, Klein I, Brochet E, Thabut G, Arnoult F, et al. Effect of early cerebral magnetic resonance imaging on clinical decisions in infective endocarditis: a prospective study. Ann Intern Med. 2010;152(8):497-504.

14. Yong MS, Coffey S, Prendergast BD, Marasco SF, Zimmet AD, McGiffin DC, et al. Surgical management of tricuspid valve endocarditis in the current era: a review. Int J Cardiol. 2016;202:44-8.

15. Yanagawa B, Pettersson GB, Habib G, Ruel M, Saposnik G, Latter DA et al. Surgical management of infective endocarditis complicated by embolic stroke: practical recommendations for clinicians. Circulation. 2016;134(17):1280-92.

16. Cabell CH, Abrutyn E, Fowler VG, Hoen B, Miro JM, Corey GR, et al. Use of surgery in patients with native valve infective endocarditis: results from the international collaboration on endocarditis merged database. Am Heart J. 2005;150(5):1092-8.

17. Gálvez-Acebal J, Almendro-Delia M, Ruiz J, de Alarcón A, Martínez-Marcos FJ, Reguera JM, et al. Influence of early surgical treatment on the prognosis of left-sided infective endocarditis: a multicenter cohort study. Mayo Clin Proc. 2014;89(10):1397-405. 